\title{
Automated Fiber Placement Manufactured Composites for Science Applications
}

\author{
Kenneth N. Segal' ${ }^{1}$, Charles He ${ }^{2}$, Will Guin ${ }^{3}$, Justin Jackson ${ }^{3}$, Ray Granoble ${ }^{4}$, Thuan \\ Nguyen $^{4}$, Lloyd Nelson ${ }^{5}$ \\ ${ }^{1}$ NASA Goddard Space Flight Center \\ ${ }^{2}$ NASA Goddard Space Flight Center / Ball Aerospace \\ ${ }^{3}$ NASA Marshal Space Flight Center \\ ${ }^{4}$ NASA Langley Research Center \\ ${ }^{5}$ Tencate Advanced Composites, Morgan Hill, CA
}




\begin{abstract}
Science instruments with large collecting areas that maintain dimensional stability, such as James Webb Space Telescope and Wide Field Space Telescope, help achieve next generation science advancements. Composite materials often used for science applications include high modulus fibers in cyanate ester matrices to result in dimensionally stable structures with low contamination. Hand lay-up fabrication is the most common approach for science instrument structures. Automated Fiber Placement (AFP) using intermediate modulus fibers is commonplace in aircraft production reducing manufacturing time and increasing quality and consistency. AFP manufacturing for future large science instruments can similarly reduce costs and increase reliability. However, high modulus fibers are more prone to damage than intermediate modulus fibers. This study investigates the manufacturing viability of M55J/RS3C (Tencate) slit tape material using AFP processing. Tencate provides slit tape materials. NASA Langley Research Center (LaRC) manufactured hand layup and AFP lay-up laminates under room temperature for initial trials, Marshall Space Flight Center (MSFC) manufactured AFP laminates under room temperature and elevated temperature conditions to evaluate processing affects. Goddard Space Flight Center (GSFC) tests and evaluates tension and Coefficient of Thermal Expansion (CTE) properties by hand lay-up and AFP slit tape automated manufacturing for large science applications. These results show processing material warm reduces process induced fiber fracture; leading to stiffness and CTE properties consistent with hand lay-up, while observing a slight degradation in tensile strength.
\end{abstract}




\section{INTRODUCTION}

\subsection{Purpose}

Space based observatories often have optical dimensional stability requirements in the micrometer range under challenging thermal and mechanical loading environments. Future space observatories plan larger primary mirrors for greater light gathering capabilities and higher resolution. National Aeronautics and Space Administration (NASA) is studying the Large Ultra Violet Optical InfraRed Surveyor (LUVOIR) with an aperture 1.2 to 2.2 times larger than James Web Space Telescope (JWST) aperture (1). NASA's new heavy lift launch vehicle with an 8.4meter (27.6 feet) diameter fairing further enables large observatory implementation. Past and current observatories such as Hubble Space Telescope, JWST and Wide Field Infra-Red Space Telescope rely on carbon fiber reinforced polymer composites material structures for high stiffness and near zero coefficient of expansion (CTE) designs. Almost exclusively these structures use polyacrylonitrile (PAN) fibers such as Toray’s M55J, and low moisture absorbing cyanate ester polymers such as Tencate's RS3 or Hexcel's 954. These observatory composite structures are manufactured using hand layup approaches. Future observatories using automated composite manufacturing, employed in aircraft production, can reduced manufacturing costs, and improve part quality and reliability. Changing composite processing can change composite properties; accordingly, we investigate automated composite manufacturing for observatory materials designs. The purpose of this work is to establish if high stiffness fiber pre-impregnated composites (herein called 'pre-preg') processed with automated manufacturing can achieve stiffness, strength and the CTE needed for dimensionally stable observatories.

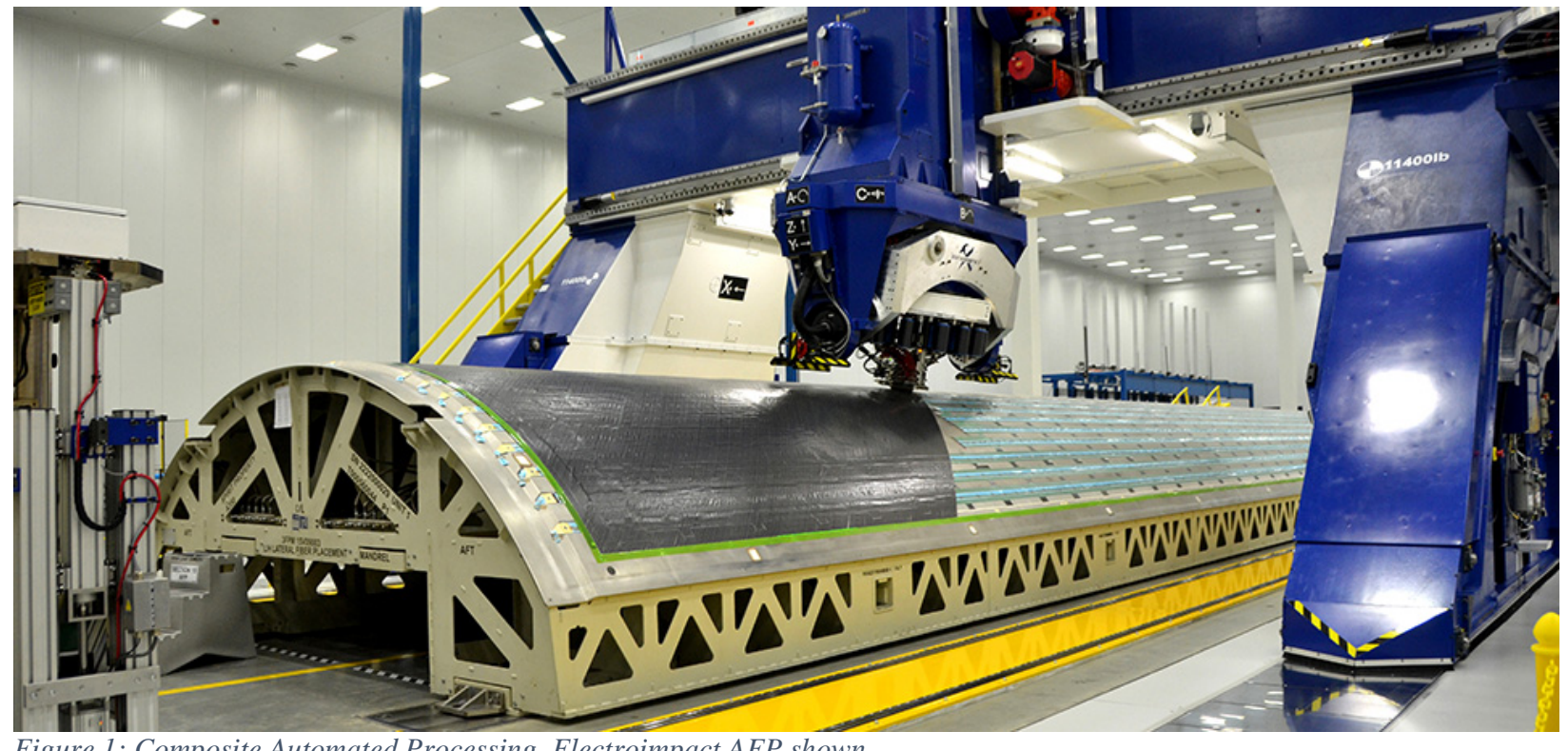

Figure 1: Composite Automated Processing, Electroimpact AFP shown 


\subsection{The Manufacturing Challenge}

Space based optically stable composite structures are commonly manufactured using hand lay-up approaches whereas composite airframe structures extensively use automation. Automation studies done on the effects of defects from gaps, overlaps, and twists, shows effect on lamina properties is around $5 \%$ (2). These are on intermediate modulus aircraft based materials, and not on high stiffness fibers found in space observatories. The high stiffness fibers are brittle compared to intermediate modulus fibers and have more tendency to fracture, and fiber fracture can affect performance. Experienced people doing hand layup can mitigate fiber fracture by gently manipulating the material with heat and pressure where geometry dictates, thus those fiber's brittle nature is not a big issue in hand layup. The automated process, on the other hand, the fibers go through prepreg tape slit operations and go through robotic heads with winding paths, pneumatic brakes and cutters that can fracture fibers. Automated Fiber Placement (AFP) using M55J/RS3C material studies here assess if manufacturing dimensionally stable space structures space structures with high stiffness fibers is viable. The metrics used to establish AFP viability compared to hand layup are fiber break counts, lamina strength and stiffness, and laminate coefficient of thermal expansion.

\section{EXPERIMENTATION}

\subsection{The Materials}

GSFC dimensionally stable structures almost exclusively use M55J with cyanate esters matrix material in unidirectional form. Tencate's RS3 and RS3C, the modified flow version of RS3, as well as Hexcel's 954-3 and 954-6 are the cyanate esters GSFC commonly uses. Tencate teamed with NASA on this work, providing material to test and assisting in with potential fiber crack issues. The material selected is M55J 6K tow fibers impregnated with RS3C at 145 grams per square meter (GSM). This selection is relevant to existing materials used now and with past flight heritage. The material specified results in a nominal cure ply thickness of $0.137 \mathrm{~mm}$ at $60 \%$ fiber volume, the thickness used for data normalization. Tencate reports 1999 MPa (290 Ksi) tensile strength and 318.5 GPa (46.2 Msi) tensile modulus in the fiber direction. These baseline properties are the comparison basis for hand layup and slit tape-processed materials.

The experimentation used three material lots, one lot for hand layup, a first lot for LaRC slit tape processing, and a second lot for slit tape processing at MSFC. The slit tape material lots are, at the time of manufacture, in compliance with out-time and shelf life. The GSFC lot for hand layup are, at the time of manufacture, with-in out time limits and out of date with respect to shelf life. Three (3) glass transition temperature, (10) short beam shear, and (3) fiber volume tests exceeded requirements to effectively extended the shelf life. Data in the testing further confirmed the adequacy of the hand laid materials as the results show.

\subsection{The Manufacturing Methods}

Hand layup and AFP methods were trialed. I assume the reader understands hand layup. AFP manufactured composite laminate processing differ from hand layup processing in two fundamental areas, material manufacturing to achieve the slit tape product, and laminate manufacturing. Tencate performed material manufacturing followed by tape slitting at their Morgan Hill, CA facility. NASA sister AFP systems exist at LaRC and MSFC (fig 2). The 
machining centers are nearly identical; both made by Electro-Impact and procured to the same technical specifications. The differences being layup platform types and positioning. For the purposes of this work, the machines are effectively identical performing automated lay. Those robots use the 16 rolls of $6 \mathrm{~mm}$ (1/4 inch) slit tape material to apply a $102 \mathrm{~mm}$ (4 inch) wide pass. The feed-rate, heater, roller type, and pressure between the two systems were kept the same to start to perform laminate manufacturing, and varied temperature processing for cracking evaluations.

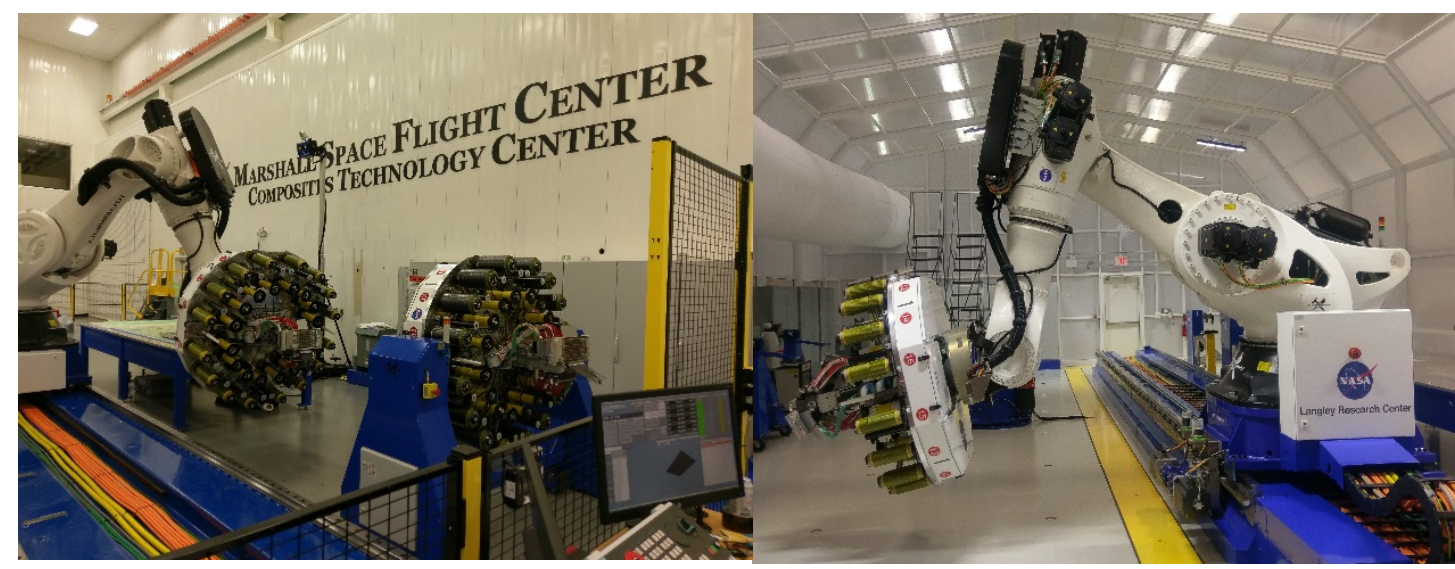

Figure 2: MSFC and LaRC Electoimpact AFP Machine Centers

\subsubsection{Slit Tape Manufacturing}

Slit tape materials come from traditional prepreg processing, and then go through secondary processing to reduce the material to slit tape width of a specified size. The slitting process done by Tencate for this effort reduced at $305 \mathrm{~mm}$ (12 inch) unidirectional tape roll first into three $102 \mathrm{~mm}$ (4 inch) rolls, and then using a slitter reduced the $102 \mathrm{~mm}$ rolls to 16 individual $6 \mathrm{~mm}$ ( $1 / 4$ inch) rolls. Figure 3 shows the $102 \mathrm{~mm}$ (4-inch) prepreg material at the beginning of the slitter, a final a $6 \mathrm{~mm}$ slit tape roll, and the circuitous route of the tape slitting process. That circuitous route that might produce cracking after pre-preg process is complete. To evaluate cracking due to slitting two different slit processing temperatures were trialed, $22^{0} \mathrm{C}\left(72^{\circ} \mathrm{F}\right)$ and $26^{\circ} \mathrm{C}\left(79^{0} \mathrm{~F}\right)$. Inspections and tests from each lot identified the effect of tape slit processing on lamina performance. 


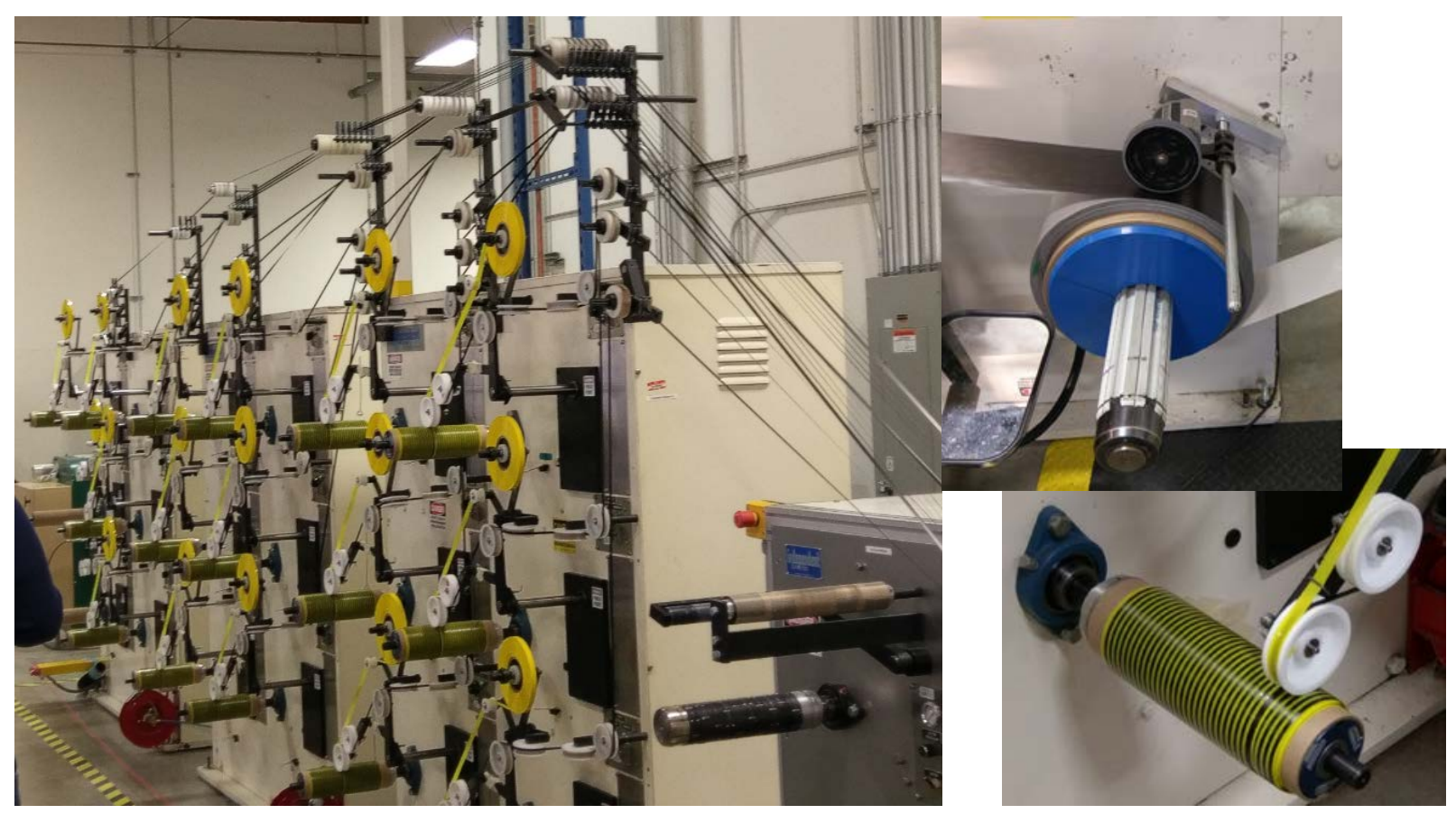

Figure 3: Tencate tape slit processing. A) Top right picture shows the original $102 \mathrm{~mm}$ (4 inch) tape material on $280 \mathrm{~mm}$ dowel . B) Bottom right picture shows the processes $6 \mathrm{~mm}$ (1/4 inch) slit tape on a $76 \mathrm{~mm}$ (3 inch) dowel.

\subsubsection{Laminate Manufacturing}

Laminate manufacturing and processing limit variability as best as possible. Cure's completed all used the same vacuume ( $94.8 \mathrm{KPa}(28 \mathrm{in}-\mathrm{hg})$ ), pressure (689.5 KPa (100 psi)) and temperature (ramp to $177^{\circ} \mathrm{C}\left(350^{\circ} \mathrm{F}\right)$ and hold for 2 hrs) as found in the RS3C datasheet. LaRC and MSFC team members communicated and used the same machine parameters for feed, speed, applied heat and pressure. The AFP variables were different room processing temperature. When higher room processing temperature occurred, it followed with reduction in machine heater setting that controls a radiant heater at the machine head. LaRC used the initial slit tape material that slit at $22^{0} \mathrm{C}\left(72^{\circ} \mathrm{F}\right)$, and laminated at $21^{\circ} \mathrm{C}\left(69^{\circ} \mathrm{F}\right)$. LaRC manufactured the hand laid panels also at $21^{0} \mathrm{C}$ $\left(69^{0} \mathrm{~F}\right)$. Tencate manufactured a second batch of material, where the slitting process processed at $27^{\circ} \mathrm{C}\left(80^{\circ} \mathrm{F}\right)$. That batch of material went to MSFC. MSFC manufactured slit tape material processed at $26^{\circ} \mathrm{C}\left(79^{\circ} \mathrm{F}\right)$. MSFC laminated panels at $22^{\circ} \mathrm{C}\left(72^{0} \mathrm{~F}\right)$ and $26^{0} \mathrm{C}\left(79^{0} \mathrm{~F}\right)$.

\subsubsection{Experimental Tests}

\subsubsection{Tensile Testing}

Fiber fracture was the primary concern and motivation for this effort. A fiber dominated mechanical test property makes sense to evaluate fiber breakage. The 'Standard Test Methods for Tensile Properties of Polymer Matrix Composite Materials’, ASTM D3039, is a fiber-dominated test well used test in composites practice and used for these evaluations. The laminate made for these tests are $[0]_{6}$ in temperature and humidity controlled environments. Five samples came from each laminate. No sample conditioning occurred, and tensile tests ensued at room temperature ambient conditions. LaRC tested the LaRC manufactured laminate coupons; GSFC tested the MSFC manufactured laminate coupons. Normalization occurred using a ratio of the average 
coupon thickness of 5 measurements to the theoretical cure ply thickness per Composite Material Handbook-17.

\subsubsection{Coefficient of Thermal Expansion Testing}

Again, fiber fracture was a primary concern and even anticipated. To ensure potential AFP manufactured structures will meet the critical dimensional stability requirements associated with science instruments, CTE tests transpired. The laminate for these tests are an eight ply design, [0, $45,90,-45]$ s , to result in a near zero CTE. No preconditioning occurred. The 'Standard Test Method for Linear Thermal Expansion of Rigid Solids with Interferometry', ASTM E289-17, is a precision method for evaluating CTE and selected for the evaluations. Thermal strain measurements over a temperature range of $323 \mathrm{~K}$ to $98 \mathrm{~K}$ using a ramp rate of $1^{\circ} \mathrm{C} /$ minute in vacuum occurred. System error is less than 10 parts per million (ppm) over $300 \mathrm{~K}$ as confirmed with a single crystal silicon standard. Figure 4 shows the laser interferometer setup. Five coupons came from each LaRC laminate, and three coupons came from each MSFC laminate. Each coupon thermal expansions measurements saw at least 3 cycles from $303 \mathrm{~K}$ to $98 \mathrm{~K}$, and those cycles measurements averaged. A best fit applied to the averaged thermal expansion data resulted in a polynomial equation, whose derivative provided the CTE reported in the results. All CTE measurements occurred at GSFC.

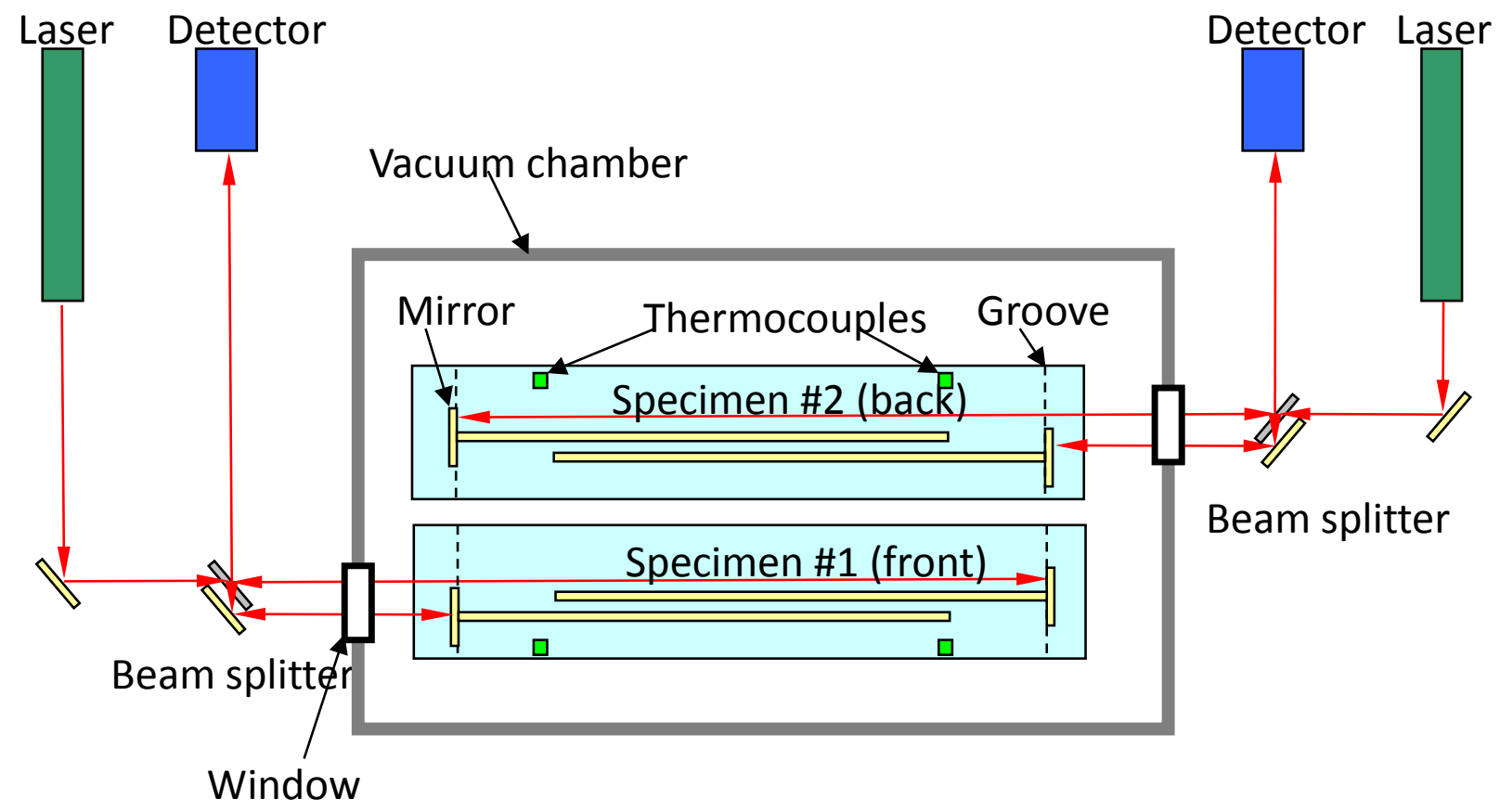

Figure 4: Laser Interferometer configuration 


\section{RESULTS}

\subsection{Material Processing}

Material evaluations consisted of visual observations of the slit tape materials and the lamination processes. Incoming materials inspection showed indications of cracking. Figure 5 shows both traditionally processed prepreg and slit tape materials. The first batch of slit tape, used in LaRC produced laminates, appears to have fractures. LaRC laminates showed fiber breakage during the processing, of 4 panels AFP processed, there were 18 fractures. Most, 14 of 18, observed fractures are at the panel edges, where the machine either starts to put material down or ends the material placement. Seeing both slit tape material cracks and lamination cracks lead to second batch of slit tape that Tencate processed differently to establish if material cracking could be eliminated.

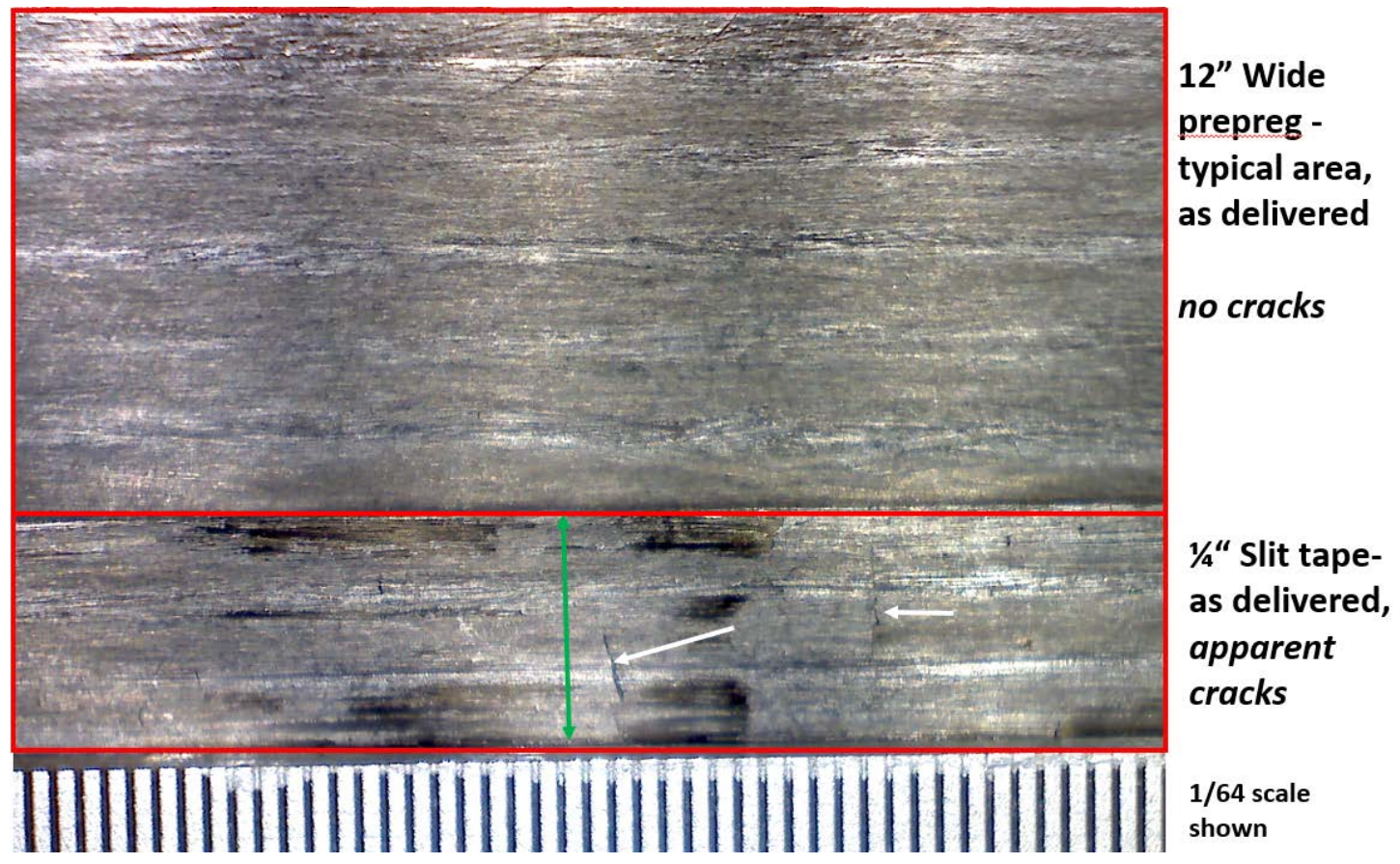

Figure 5: Images show typical prepreg (above) and slit tape with apparent cracks (below)

Tencate performed tape slitting at $27^{0} \mathrm{C}\left(80^{\circ} \mathrm{F}\right)$, used a more pliable backing material than the first lot, and lastly shipped in a manner to space individual rolls to prevent no roll to roll contact. Slit tape processed in this manner showed no apparent cracking at incoming material inspection. MSFC lamination used this second slit tape material batch. For the MSFC panels, to the same specification as LaRC panels, for 8 panels fabricated, there were 29 observed fractures, 25 of those were in one panel, the CTE test panel number 1282231-3-1, laminated at room temperature. All those cracks were within the first 2 inches from panel edges, the lead-in/lead-out, and outside the area of any test coupon cut from that panel.

\subsection{Tension Test Results}

The tension tests results compared to the Baseline data show strength reduction is a function of lamination process conditions. The Tencate RS3 datasheet baseline data shows an ultimate tensile strength in the fiber direction of $1999 \mathrm{MPa}$ (290 Ksi) and a modulus of $318.5 \mathrm{GPa}$ (46.2 Msi). All 
tensile strength and moduli data presented in figure 6 (the strength shown on the abscess, the modulus is on the ordinate). Nineteen of the 20 coupons tested failed by longitudinal splitting, as is expected with a [0]6 laminate tensile test. The one outlier failed at the tab end due to the excessive, $8.9 \mathrm{kN}$ (2000 lb-f) grip pressure being applied, that single data point is dropped from the results.

The LaRC Hand layup panel data shows agreement with the Tencate datasheet, the strength having a $3.5 \%$ difference, the modulus being $2.0 \%$ different. These are both well within one standard deviation of the hand layup test data. Furthermore, moduli values for all test data are within 6\% across the dataset. Essentially, there is no effect of AFP on moduli. The large differences in the datasets are in the Tensile strength.

AFP processed panels have lower strength than the hand layup manufacturing process. The LaRC AFP panel processed at room temperature shows the highest number of manufacturing fractures as well as a $29.7 \%$ strength reduction from baseline. Using Tencate second slit tape batch (recalling that used higher processing temperature and less stiff backing) MSFC AFP panel processed at room temperature was slight better with a strength $23.9 \%$ lower than hand layup strength. Finally, the MSFC AFP panel processed warm shows a strength recovery of about $10 \%$, being only $17.3 \%$ lower than the hand layup data. Summarizing, AFP processed slit tape material shows a tensile strength reduction, some reduction mitigated by increasing processing temperature. There is no associated change in tensile modulus.

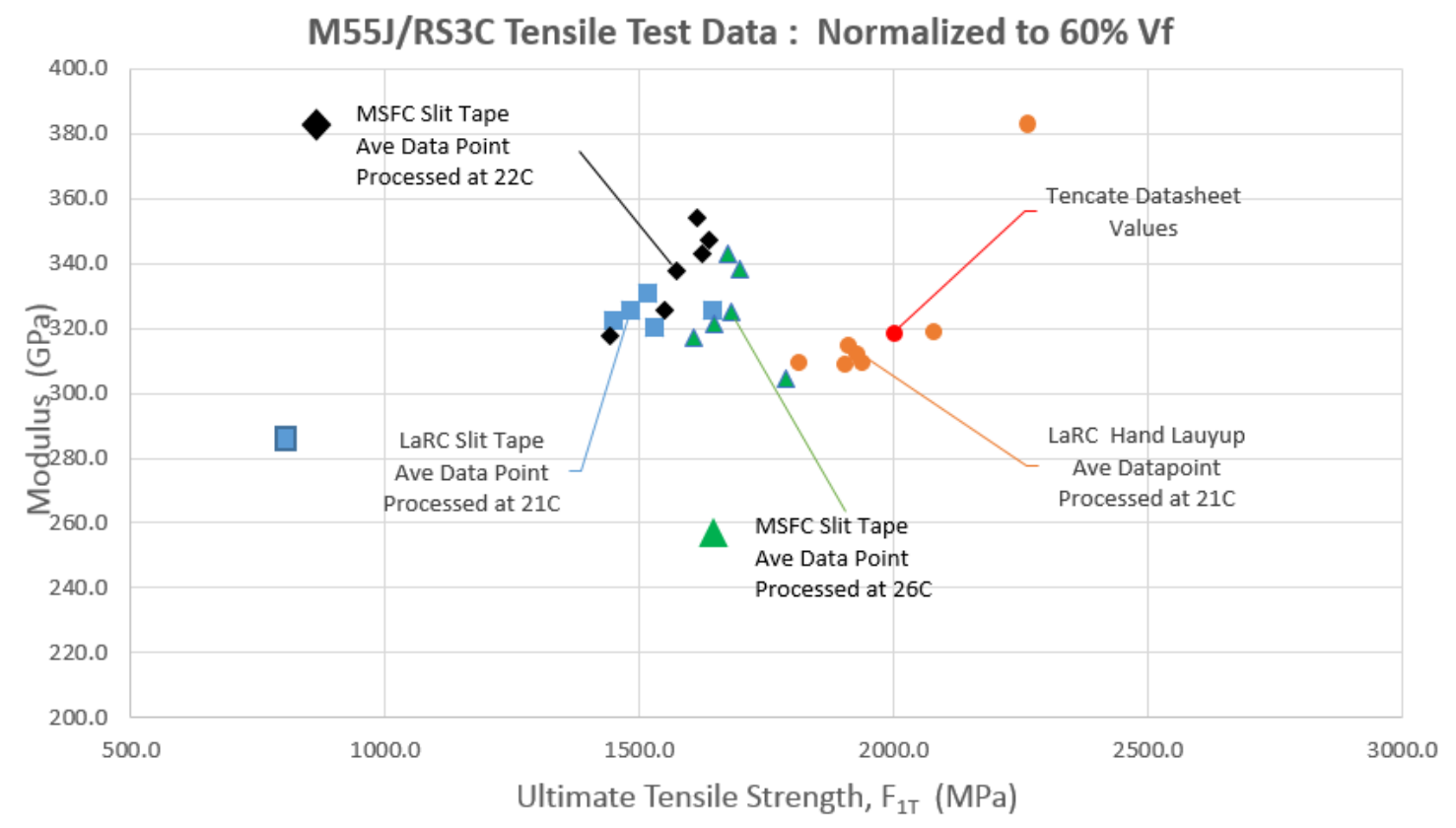

Figure 6: Fiber Tensile Strength and Modulus Data 


\subsection{Coefficient of Thermal Expansion Results}

The CTE testing results (figure 7), hand layup and AFP layup, shows the CTEs to be from 0.0 to - 0.5 part per million per degree Kelvin, and is as expected for a Quasi-isotropic M55J/RS3C laminate. The measurement data shown are two types, the raw data showing change in length to original length, and the processed CTE, a derivative of the smoothed raw data, each provided to show overall CTE as well as some coupon apparent cracking of interest. The MSFC AFP shows a more pronounced decreasing trend from $320 \mathrm{~K}$ to about $240 \mathrm{~K}$ than the LaRC panels, and this is very small variation. To try to understand this better we looked to the thermal expansion data between the two centers.

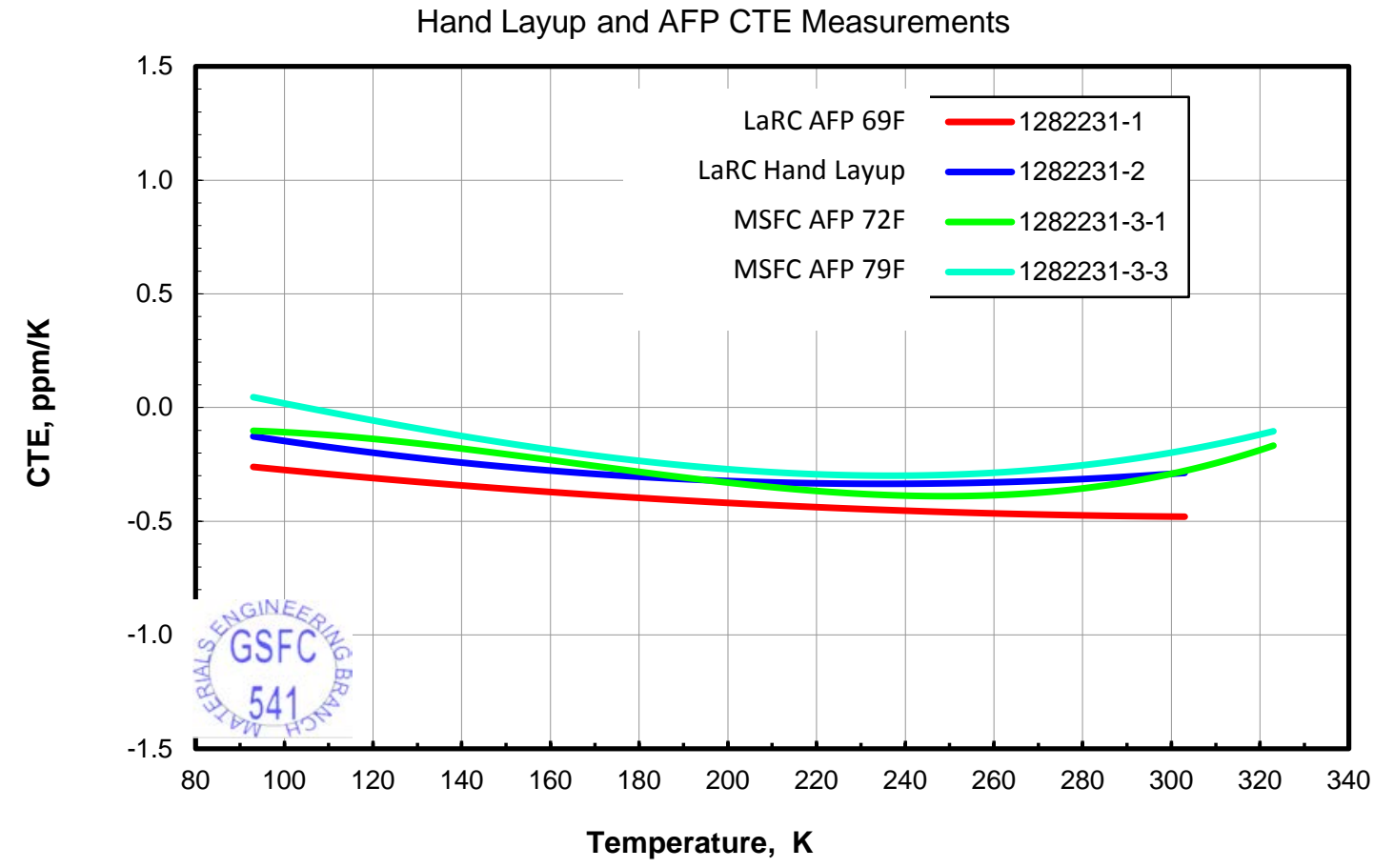

Figure 7: CTE Summary, all manufacturing approaches 


\subsubsection{LaRC CTE Results}

Figure 8 shows LaRC hand layup and AFP layup CTE results. The Handlayup CTE is -0.3 $\mathrm{ppm} / \mathrm{K}$, the AFP measured $-0.4 \mathrm{ppm} / \mathrm{K}$. As indicated before, these LaRC laminates were room temperature processed. The small difference shows that Hand layup and AFP processed QI laminates can result in the same near zero CTE over the temperature range tested.

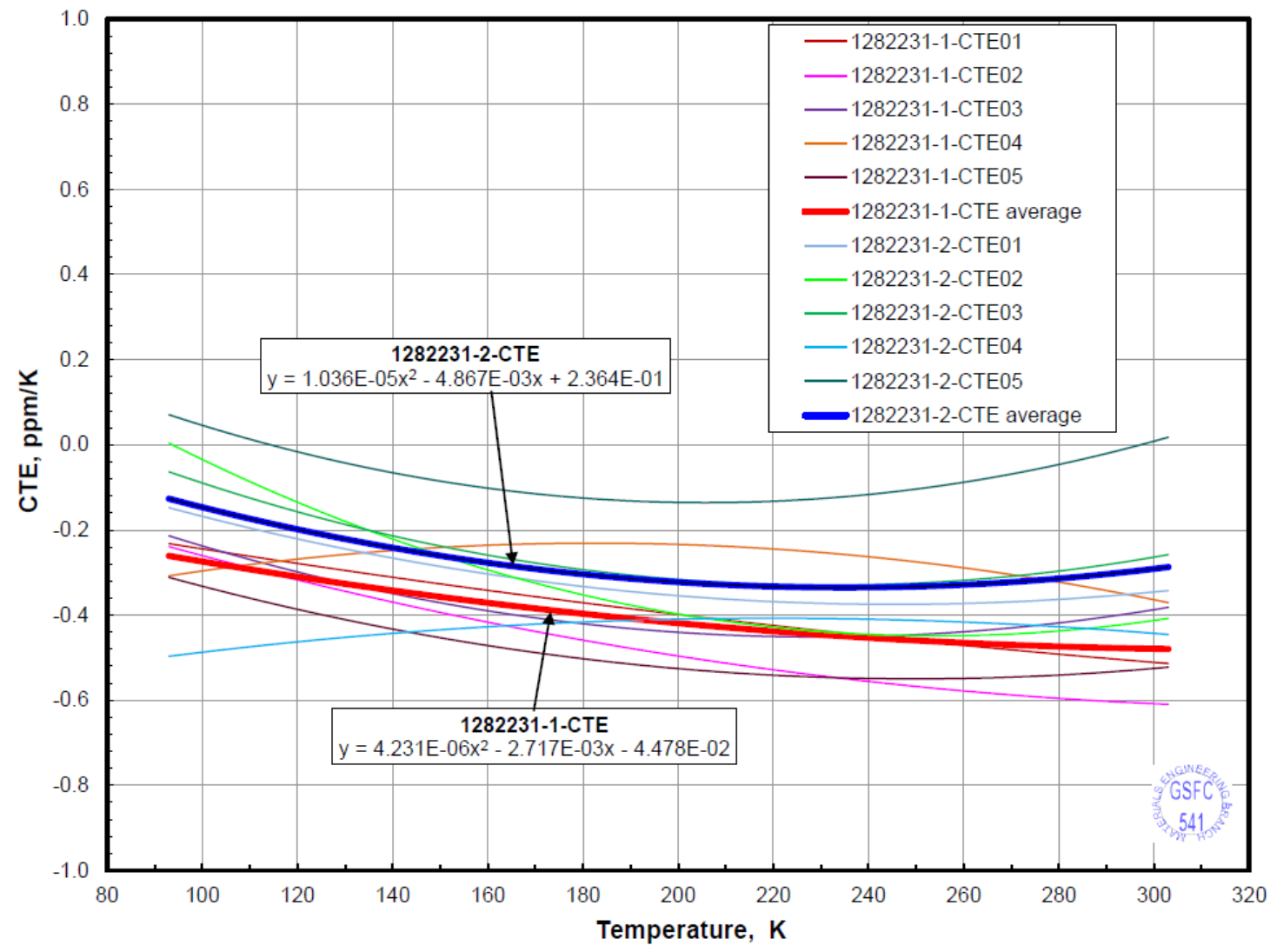

Figure 8: LaRC Average CTE over multiple coupons, Hand layup 1282231-2 panel and AFP layup 1282231-1 panel

\subsubsection{MSFC CTE Results}

Figure 9 shows MSFC AFP laminate CTE processed at $22^{\circ} \mathrm{C}\left(72^{0} \mathrm{~F}\right)$ and $26^{0} \mathrm{C}\left(79^{0} \mathrm{~F}\right)$. The $22^{0} \mathrm{C}$ $\left(72^{0} \mathrm{~F}\right.$ ) processed laminate $\mathrm{CTE}$ average over the temperature range tested is $-0.2 \mathrm{ppm} / \mathrm{K}$, the $26^{0} \mathrm{C}$ 
$\left(79^{0} \mathrm{~F}\right)$ processed CTE average is $-0.3 \mathrm{ppm} / \mathrm{K}$. The small CTE difference between the two processing temperatures indicate not apparent difference.

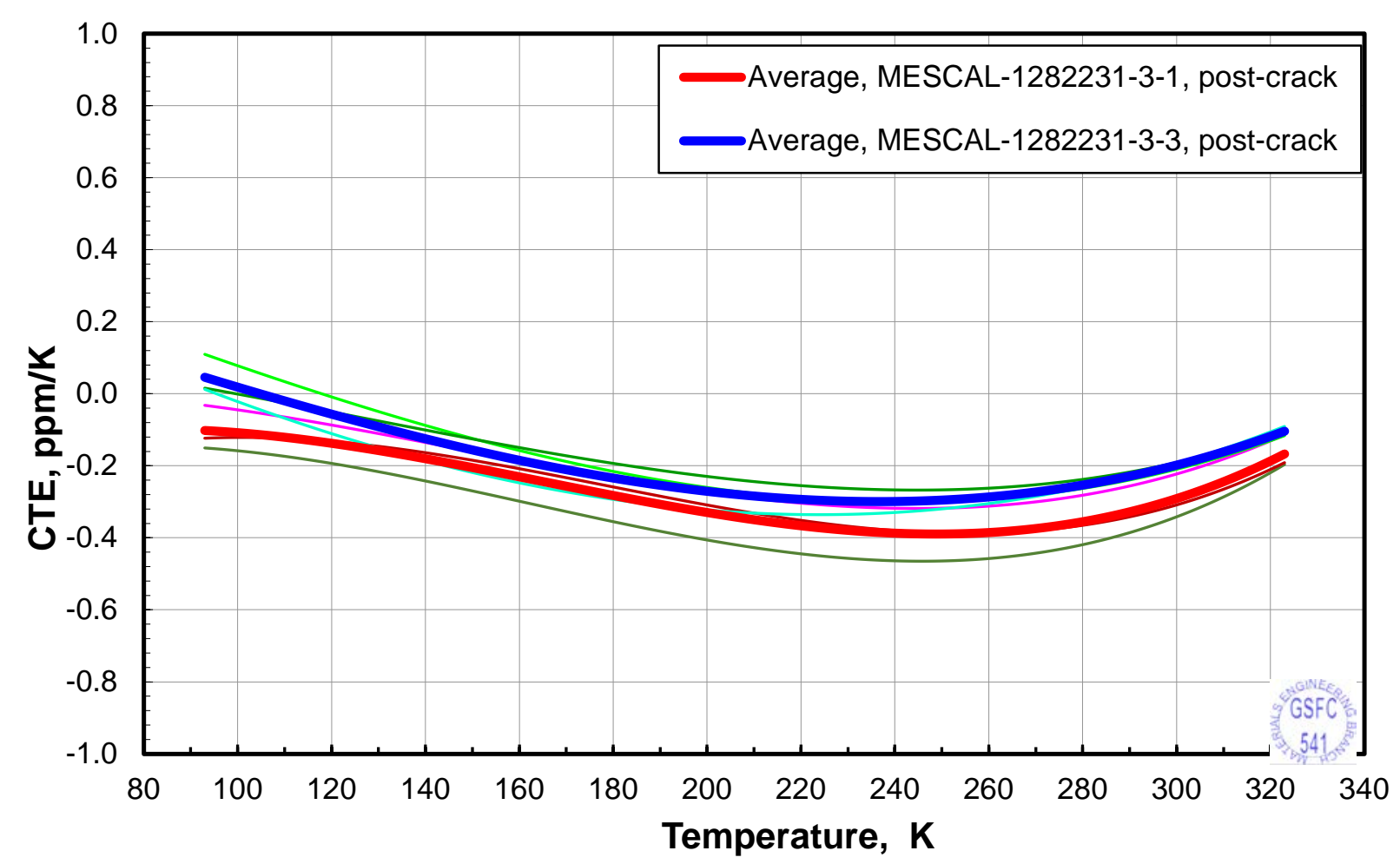

Figure 9: MSFC CTE Measurements, Post Cracking

The MSFC results differed in one aspect, there did appear to be some cracking in the MSFC AFP panels. This observation comes from the first MSFC coupon thermal deformation measurements. Figure 10 data shows thermal expansion data for all 6 MSFC AFP coupons. A response change during the first thermal cycle occurs in a range of $200 \mathrm{~K}$ down to $170 \mathrm{~K}$, where the thermal expansion curve drops and the thermal expansion data is invalid after this point in a given measurement. An event apparently disturbed the retroreflectors during the measurement. A suspected crack impulse moved the retroreflector during that first cycle cold and never repeated. Furthermore, visual observation of the laminate surface shows apparent cracks along the fibers direction (figure 11), thus we call this 'pre-cracking' in the test data. Measurements taken after the 
first cycle we call 'post cracking' and provided good measurements through the whole temperature cycle.

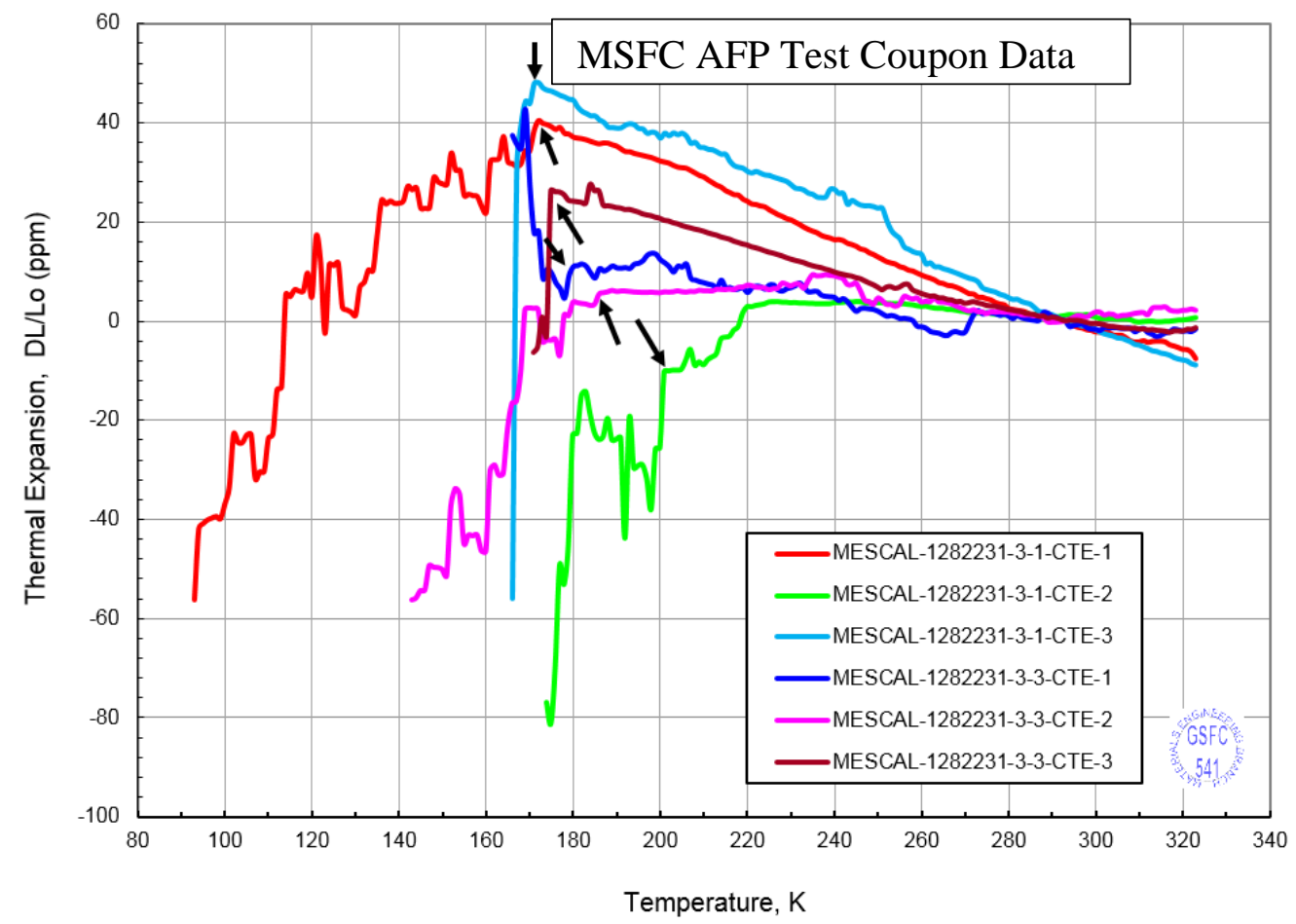

Figure 10: MSFC AFP Themal Expansion showing change in behavior

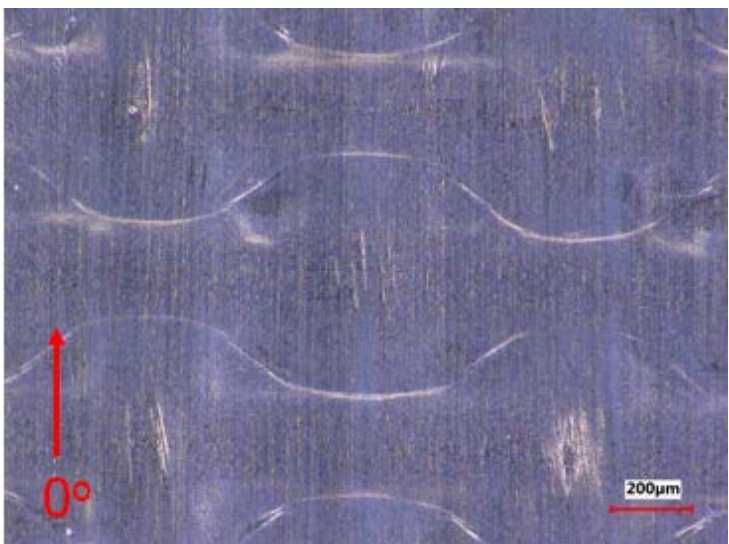

Before Thermal Cycle

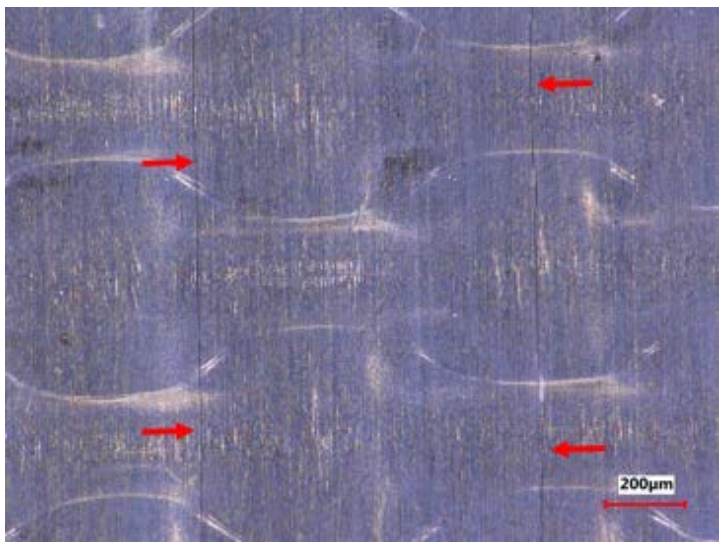

After Thermal Cycle to 93K

Figure 11: CTE coupon surface cracking observed

Figure 12 shows thermal expansion data including both pre and post cracking thermal expansion data. Data on coupons 1282231-3-3 the CTE-1 and CTE-2, from the same panel, the pre- 
cracking thermal expansion is lower than the post-cracking thermal expansion. However, the other 4 coupons show pre cracking and post cracking behavior does not change the thermal expansion. Now 1282231-3-1 CTE-3 and 1282231-3-3 CTE-3, from two different panels show little difference between pre- and post-cracking, and suggests that the cracking is not due to processing difference. Lastly, 1282231-3-1 CTE-1 and 1282231-3-3 CTE-2 only post cracking measurements were taken and are consistent with. It is noted CTE processed data is only on the post cracking, and again, the CTE are very low and cracking does not affect CTE.

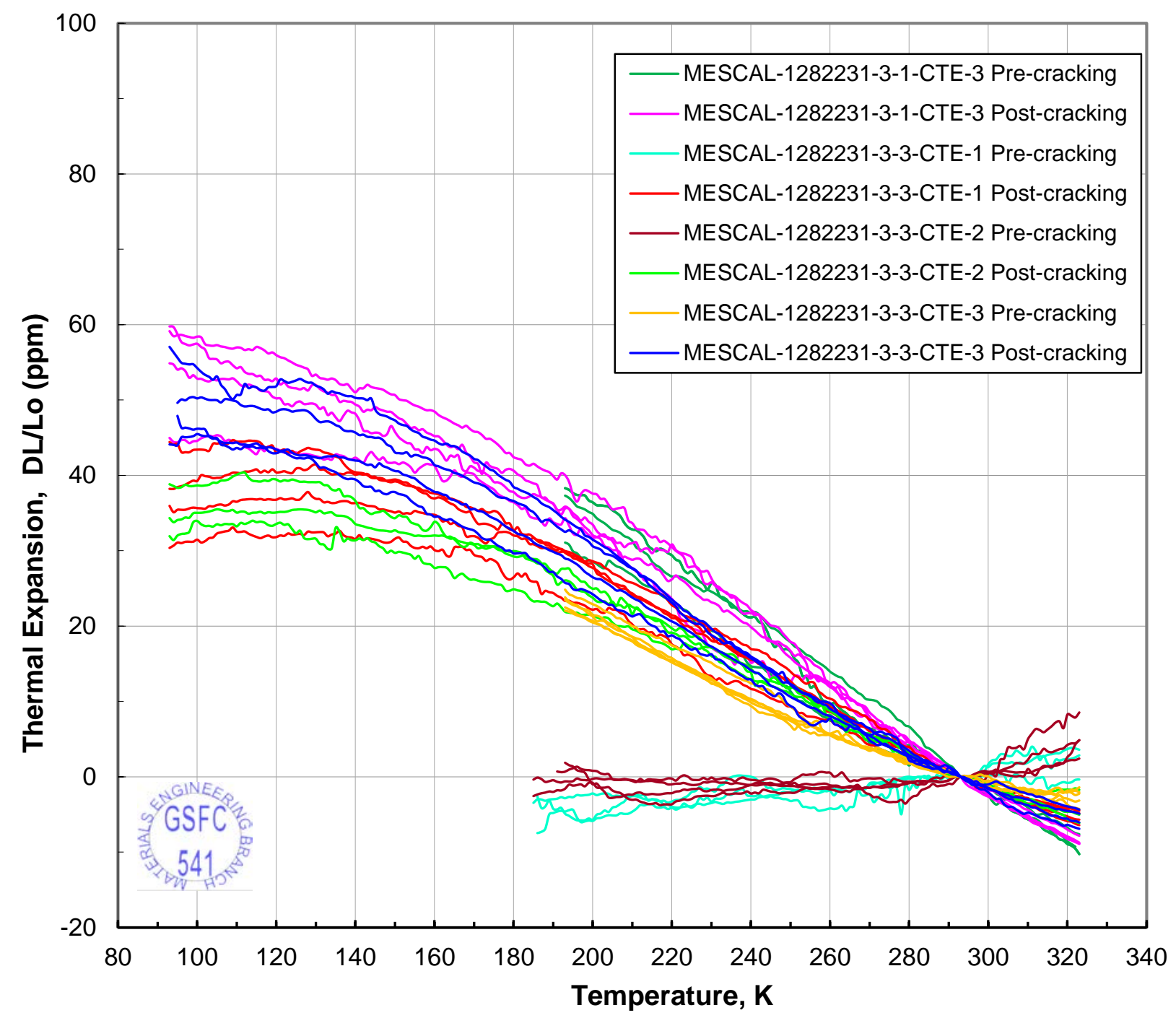

Figure 12: MSFC Panels, pre cracking and post cracking data 


\section{CONCLUSIONS}

\subsection{Material and Lamination Processing}

Tensile testing results shows that AFP processed laminates will have the expected fiber direction tensile modulus and lower strength. We conclude that cure and test approach used in this experimentation are valid based on fiber direction tensile modulus and strength publish data agreement, with $2.0 \%$ and 3.5\% differences, respectively to hand layup test data. From AFP testing, we conclude four things. First, the different in manufacturing centers had little effect on tensile modulus and strength comparison based on LaRC and MSFC AFP laminates processed at room temperature. Secondly, AFP processing M55J/RS3C at room temperature lowers tensile strength from between $23.9 \%$ to $29.7 \%$ while not effecting the tensile modulus compared to the Tencate Datasheet. Third, slitting the prepreg tape warm reduces cracking and improves tensile strength by $5.8 \%$. Forth, AFP laminates processed at warm temperature is another $12.4 \%$ tensile strength improvement over laminate processed at room temperature. Given that, only the applied temperature is to room lamination occurred, and that the robotic heads are also possible to heat, we expect more strength recovered with additional processing control measures.

\subsection{CTE Conclusion}

CTE test results show that AFP processed M55J/RS3C laminates the same CTE as hand layup processed laminates. The MSFC individual test results show that some resin fracture was occurring that did not affect CTE measurements

\subsection{What Is Proven and Next Steps}

Stiff fibers, such as M55J, processed with robotic manufacturing for science applications with no degradation on CTE, no degradation of stiffness, and a slight tensile strength degradation. Processing approaches and controls will reduce tensile strength degradations. The observed cracks in the CTE testing indicates that knowing the structure temperature is important, and future testing should include thermal cycling before testing, as well as more evaluation to characterize cracking to understand how much is fiber cracking and how much is matrix cracking. Not that those cracking instances are a limitation, more to understand the phenomenon.

\section{REFERENCES}

1. D.A Fischer, et al, LUVOIR: Surveying the cosmos and characterizing exoplanets” Astrobiology Science Conference 2017

2. Kaven Croft, et al: "Experimental Study of the effect of automated fiber placement induced defects on performance of composite laminates.” Composites: Part A 42 (2011)

3. 